\title{
Protagonismo socioeconômico das pescadoras artesanais do bairro Pérola do Maicá, em Santarém Pará
}

\section{Socioeconomic protagonism of artisanal fisherwomen from Pérola do Maicá neighborhood, in Santarém Pará}

\author{
Wandicleia Lopes de Sousa ${ }^{1}$ \\ Leila de Fátima de Oliveira Monte $e^{2}$ \\ Rubens Elias da Silva ${ }^{3}$ \\ Thiago Almeida Vieira ${ }^{4}$
}

\begin{abstract}
Resumo: Este estudo analisa o protagonismo socioeconômico de pescadoras artesanais do Bairro Pérola do Maicá em Santarém-Pará, sob o viés do trabaIho. A questão norteadora da pesquisa centra sua indagação em saber como ocorre a participação da pescadora artesanal na atividade social, econômica e familiar no bairro. A pesquisa foi realizada com $43 \%$ das mulheres pescadoras artesanais sócias do núcleo de base residentes no Bairro Pérola do Maicá, no município de Santarém. Como resultados, percebeu-se que as pescadoras artesanais possuem baixa escolaridade, demonstrando que essa categoria tem dificuldade em ter acesso a políticas públicas essenciais para o seu desenvolvimento socioeconômico. As pescadoras artesanais dedicam-se em média 16 dias do mês para exercer as atividades pesqueiras, os demais dias são dedicados para cuidar da casa, família e dos arreios usados durante a prática da atividade. Conclui-se que é necessário incentivar a atividade realizada pelas pescadoras do bairro Pérola do Maicá, valorizando a característica artesanal e sustentável do ofício, desta forma, fomentando, a pesca artesanal no município de Santarém-PA, e reconhecendo o trabalho realizado pelas pescadoras.

Palavras-chave: Mulher, Pesca Artesanal, Lago do Maicá.
\end{abstract}

Abstract: This study analyzes the socio and economic protagonism of artisanal fisherwomen from the Pérola do Maicá a neighborhood in Santarém-Pará. The guiding question of the research focuses in its inquiry about how the artisanal fisherwomen's participation in the social, economic and family activity in the neighborhood happens. The survey was carried out with $43 \%$ of the women artisanal fisherwomen of the base nucleus residents in the Pérola do Maicá neighborhood, in the municipality of Santarém. As results, it was noticed that artisanal fisherwomen have low levels of education, demonstrating that this category has difficulty accessing essential public policies for their socioeconomic development. The artisanal fisherwomen dedicate themselves in average 16

\footnotetext{
${ }^{1}$ Discente do mestrado em Sociedade, Ambiente e Qualidade de Vida (PPGSAQ) da UFOPA. E-mail: wandicleia@hotmail.com.

${ }^{2}$ Docente do Curso de Ciências Econômicas da Universidade Federal do Oeste do Pará (UFOPA). Email: leila.monte@ufopa.gov.br.

${ }^{3}$ Docente do Mestrado em Sociedade, Ambiente e Qualidade de Vida- PPGSAQ/UFOPA e do Mestrado em Ciências da Sociedade/UFOPA. E-mail: hellazer09@gmail.com.

${ }^{4}$ Docente do Mestrado em Sociedade, Ambiente e Qualidade De Vida- PPGSAQ. E-mail: thiago.vieira@ufopa.edu.br.
} 
days of the month to carry out the fishing activities, the other days are dedicated to take care of the house, family and of the harnesses used during the practice of the activity. Finally it is concluded that it is necessary to encourage the activity carried out by the fisherwomen of the Pérola do Maicá neighborhood, valuing the artisanal and sustainable characteristic of the craft, thus encouraging artisanal fishing in the municipality of Santarém-PA, and recognizing the work done by the fisherwomen.

Keywords: Woman, Artisanal Fishing, Maicá Lake.

\section{Introdução}

A mulher tem buscado conquistar seu espaço dentro do mercado de trabalho. Esse esforço tem trazido um novo cenário de reflexão sobre os espaços produtivos e reprodutivos da mulher na sociedade, uma vez que numa perspectiva histórica a esfera do trabalho pesqueiro era de dominação masculina, dada a uma hegemonia atribuída por homens para homens (BOURDIEU, 2003). Ainda mais, em atividades tradicionais como a pesca artesanal, a predominância da força de trabalho masculina tornou-se evidente, inclusive, nos inúmeros trabalhos antropológicos dedicados ao tema. Paulatinamente, esses estudos recentes principalmente na área antropológica e sociológica tem dado uma perspectiva peculiar a respeito da esfera do trabalho pesqueiro exercido por pescadoras artesanais, seus dilemas, paradoxos, enfrentamentos e filiações (LEITÃO, 2013; HELLENBRANDT, RIAL e LEITÃO, 2016). Nessa perspectiva, no presente estudo, procura-se lançar luz sobre como esse protagonismo feminino no mundo da pesca tem se construído por um processo de invisibilização e políticas públicas incipientes no setor. Paradoxalmente, esse protagonismo foi sendo estruturado justamente pela falta de espaço que as pescadoras foram forçadas a enfrentar e a questionar.

Isso ocorre devido a pesca artesanal ser vista como uma atividade exercida primordialmente por homens, sempre considerado como responsável pelo sustento e orçamento familiar, cujas normas sociais ordenam o espaço doméstico à atuação feminina, gerando desigualdades de gênero (SORJ, 2010). E não somente isso: somente no início dos anos 2000 que as mulheres pescadoras puderam ser contempladas por instrumentos de políticas públicas como o seguro defeso.

Essa realidade se agravou com a edição do decreto $n^{\circ} 8.425 / 2015$, que dispõe sobre os critérios para inscrição no Registro Geral da Atividade Pesqueira e para a con- 
cessão de autorização, permissão ou licença para o exercício da atividade pesqueira, esse Decreto descreve o trabalho da mulher como meramente auxiliar na atividade da pesca, tirando-Ihes os direitos conquistados ao longo de muitas lutas. Assim, como o Estado não as considera como trabalhadoras de factum, essas enfrentam dificuldades em acessar os poucos benefícios disponibilizados a classe; além disso, desenvolvem suas atividades produtivas sem cobertura previdenciária.

Contradizendo o decreto, a figura feminina desempenha uma função importante dentro da cadeia produtiva pré e pós-captura, sendo responsável na maioria das vezes pelo beneficiamento, comercialização e fabricação dos arreios na atividade pesqueira (FIGUEIREDO; PROST, 2014, p.83). Entender o papel exercido pela pescadora nesse universo é essencial, pois, é possível mensurar a valorização de seu esforço e em consequência disso, desmistificar a invisibilidade de sua mão de obra dentro da atividade pesqueira.

A análise parte do contexto histórico das relações entre gêneros, em que as muIheres têm sido considerado como mera coadjuvante no desenvolvimento das atividades produtivas. Como as pescadoras analisadas aqui vem construindo um determinado cenário de protagonismo socioeconômico, em cujo cenário social que ainda é organizado a partir de uma ideologia e dominação masculina? É neste cenário que, atualmente mulheres pescadoras artesanais de Santarém passam a assumir o sustento de suas famílias, ganhando destaque e reconhecimento da importância do seu papel no processo produtivo local, superando a sombra de ver seu trabalho como "mão de obra" secundária ao trabalho masculino.

Santarém é um município em que a pesca artesanal é desenvolvida por homens e mulheres, que utilizam os inúmeros rios, lagos, lagoas e paranás para a obtenção do recurso pesqueiro. Além disso, o município é considerado estratégico no contexto socioeconômico da região do Baixo Amazonas Paraense. Devido aos seus ecossistemas e particularidades da região, a cidade é considerada um dos polos de comercialização e produção pesqueira mais importantes da região e do estado (ISAAC; BARTHEM, 1995). As cidades na região amazônica são marcadas por características como lagos, igarapés e furos de rios, formando paisagens exuberantes que encantam por suas belezas 
naturais, além de exercer a importante função de berçário para reprodução de diversas espécies de peixes existentes na região.

Apresentando essas particularidades que são fundamentais na atividade pesqueira encontra-se o lago do Maicá, abrangendo um território de aproximadamente 161 $\mathrm{km}^{2}$, tendo parte de sua extensão localizada na área urbana do município de Santarém, possuindo um ecossistema predominantemente caracterizado como o ambiente de várzea. Além disso, esta região é composta por um conjunto de lagos oriundos do Rio Amazonas, interligado com a região do Ituquí (VAZ, 2016). A dinâmica de seu ecossistema torna o lago um "berçário natural", por propiciar a reprodução de peixes, quelônios, aves, além de possuir uma "biodiversidade de plantas aquáticas todas típicas da região amazônica que possui grande importância ambiental para o território" (SOUSA, 2017, p.40; VAZ, 2016).

Dentro desse espaço territorial está o Bairro Pérola do Maicá, onde residem aproximadamente 19 pescadoras artesanais, associadas ao núcleo de base da Colônia de Pescadores Z-20 existente no referido bairro, que utilizam a pesca como meio de subsistência. O objetivo deste estudo é descrever o trabalho que essas pescadoras desenvolvem na atividade pesqueira e, averiguar como é construído o reconhecimento da sua identidade profissional na Colônia dos Pescadores. A questão norteadora da pesquisa centra na indagação de saber como vem ocorrendo a participação da pescadora artesanal na atividade socioeconômica e familiar no espaço lócus da pesquisa.

O estudo está organizado em quatro partes, incluindo esta introdução. A segunda parte faz uma descrição sobre o protagonismo feminino na pesca artesanal no contexto Brasileiro e na Amazônia. A terceira parte apresenta dados sobre a (in)visibilidade econômica e social das pescadoras artesanais do Bairro Pérola do Maicá, detalhando os procedimentos metodológicos utilizados no decorrer da pesquisa. Na quarta parte são apresentadas as considerações finais.

\section{O PROTAGONISMO FEMININO NA PESCA ARTESANAL NO BRASIL E NA AMAZÔNIA}

Desde a era primitiva a mulher sempre ocupou espaços descritos como de pouca importância dentro do contexto social, pois, era vista como uma pessoa do sexo infe- 
rior ou sem capacidade para realizar atividades que exigiam grande responsabilidade. Historicamente tem se comparado as atividades executadas pelas mulheres com as realizadas pelos homens, estes últimos geralmente eram descritos como responsáveis de assumir as atividades que exigiam o uso da força para sustentar a família, como a pesca e a caça enquanto que ao trabalho feminino é restava o reconhecimento como atividade secundária e de menos importância (OLIVEIRA; SAMPAIO, 2002).

Historicamente no Brasil, a figura feminina esteve ligada a mera condição de coadjuvante no processo produtivo e reprodutivo descritas como mero apêndice das ações desempenhadas pelos homens. Segundo Santos (2017, p.2), "invisíveis e alijadas de qualquer destaque social, as mulheres permaneceram na penumbra da história por vários séculos". Na atividade da pesca artesanal essa relação entre homens e mulheres, não se difere, pois, é definida na sua maioria pela questão do gênero, onde o homem é considerado como o responsável pela esfera produtiva e a mulher apenas como capaz de garantir a procriação (KERGOART,2003).

A partir dos anos de 1970 essa realidade foi se modificando e as mulheres começaram a se destacar pela sua participação nas lutas sociais, sindicais e recentemente na política, essas mudanças ocorreram sobre grande influência dos movimentos de mulheres do país (LEONE; TEIXEIRA, 2010). Essa década marcou o início da valorização da força feminina na realização das atividades produtivas, tornando-se um divisor de águas na participação da mulher em atividades econômicas importantes. Nas décadas seguintes a valorização de sua mão de obra foi aumentando, de modo especial, com a chegada da industrialização e a terceirização da economia (HOFFMANN e LEONE 2004).

Inicialmente, as mulheres tinham envolvimento indireto no desenvolvimento da atividade da pesca sendo responsáveis apenas pelo beneficiamento, comercialização do pescado e pelo concerto dos arreios utilizados durante a pescaria. Com a mudança do papel da mulher no seio familiar, sendo elas muitas vezes responsáveis pelo sustento da família, mesmo com as dificuldades socioeconômicas, característica comum às comunidades que sobrevivem da exploração dos recursos pesqueiros, estas contribuíram significativamente para a inserção da mulher de forma direta na pesca (MARTINS e ALVIM, 2016, p.380) passam a assumir mais uma atividade dentro da pesca sendo agora 
também responsáveis pela captura do pescado.

A atividade da pesca artesanal na região amazônica é realizada em regime familiar, onde o trabalho é dividido entre marido, mulher e os filhos, ou seja, todos os membros da família são envolvidos em seu desenvolvimento. No entanto, as questões das relações produtivas e econômicas estão intimamente interligadas, uma vez que as unidades familiares nessa região desempenham o papel de produtor e consumidor simultaneamente (ALMEIDA, 2013), onde uma atividade complementa a outra, permitindo gerar renda familiar capaz de reprodução social (WOORTMAN, 1992).

Nesse cenário, apesar da organização na distribuição de tarefas, entre as forças existentes no seio familiar, a mulher desempenha papel preponderante no processo produtivo, negando assim, a lógica de que a mulher desempenha papel secundário dentro da atividade da pesca artesanal. Assim, o trabalho produtivo e reprodutivo se torna parte integrante do cotidiano da classe feminina.

Ao discutirmos a configuração da organização social do trabalho na pesca, enfatizamos o modelo bipolar de divisão, determinada por idade e pelo sexo, assentada na hierarquia doméstica e na relação da força produtiva humana, que caracteriza a distinção das tarefas, e mesmo com domínio eminentemente masculino, a mulher é peça fundamental a atuar no campo de transformação, seja longe ou próximo dos rios e várzeas (fora ou dentro do lar) (ALMEIDA, 2013, p.94).

Assumindo mais responsabilidades no desenvolvimento da atividade da pesca artesanal, as mulheres começaram a se mobilizar em busca de garantir equidade no acesso às políticas públicas, na seguridade social e previdenciária direcionadas ao setor pesqueiro. Essa movimentação ajudou a diminuir as desigualdades históricas existente, dando maior visibilidade na inserção do sexo feminino por esta atividade produtiva. processo de conquista de direitos contou com o apoio de importantes entidades sociais, sindicais e de pesquisa que ajudaram as pescadoras em seu empoderamento social, político e econômico.

O processo de empoderamento das pescadoras ocorreu com a articulação de uma ampla rede de apoio e de discussão política, que inclui parcerias com pesquisadores, Organizações da sociedade civil nacional e internacionais, e instituições de representação dos pescadores. Dentre as principais estão o MONAPE (Movimento Nacional dos Pescadores) com forte atuação nos anos 1990; a CPP (Comissão Pastoral da Pesca) que mantem forte atuação junto à categoria dos pescadores e pescadoras artesanais; o ICSF (Coletivo Internacional de Apoio aos Tra- 
balhadores da Pesca) com forte atuação em países em desenvolvimento (ALENCAR et al., 2015, p. 8).

Como resultado do empoderamento e mobilização social das pescadoras artesanais, elas começam a assumir cargos importantes nas organizações sindicais e sociais que representam a classe. Em 1989, foi eleita, Joana Rodrigues Mousinho, a primeira pescadora como presidente da Colônia de Pescadores Z 10, da cidade de Itapissuma, Estado de Pernambuco. Essa eleição foi um marco na história das pescadoras artesanais, vez que nas entidades que representavam a classe apenas os homens assumiam função de direção, deixando assim a mulher excluída do debate sobre as políticas públicas e do processo organizativo das entidades que as representavam (LEITÃO, 2014).

Atualmente, de acordo com a Federação dos Pescadores Artesanais do Estado do Pará, o total existente de pescadoras artesanais é de aproximadamente 12 mil, o que representa $10 \%$ do total geral estimado de pescadores artesanais exercendo a atividade da pesca no estado. Na região do Baixo Amazonas (Pará), atualmente existem 13 colônias de pescadores artesanais, dentre essas apenas em 07 entidades existem mulheres compondo a direção, e nesse universo somente em 03 Colônias assumem o cargo de presidente. Em Santarém, desde 1982 as mulheres conquistaram espaço dentro da direção da Colônia de Pescadores Z-20, inclusive, no ano de 2017 uma pescadora assumiu a direção de finanças e patrimônio da entidade (PINTO, 2016).

\section{CAMINHOS METODOLÓGICOS}

O percurso metodológico da pesquisa procurou revelar os pressupostos teóricos e metodológicos usados para realizar esse estudo, que pode ser entendido como de cunho quantitativo e qualitativo, ao complementarem-se para alcançar os objetivos traçados. Na pesquisa quantitativa usou-se como instrumento para coleta de o formulário de entrevistas e observações das reuniões técnica que ajudou a coleta de dados para fazer a descrição do perfil socioeconômico das participantes da pesquisa. Enquanto que a pesquisa qualitativa auxiliou na análise das informações coletadas no grupo pesquisado possibilitando interpretação minuciosa dos processos sociais e a interpretação das particularidades dos comportamentos ou atitudes dos indivíduos. (OLIVEIRA, 2008).

Usou-se ainda como aporte metodológico a pesquisa descritiva que auxiliou na 
uniformização no processo de planejamento, coleta e análise dos dados. As técnicas usadas compõem características do estudo de caso e contribuíram para realização de um exame detalhado dos fatos, da dinâmica social, familiar e organizativo das pescadoras artesanais. A partir da utilização desses métodos foi possível perceber na vivência diária do grupo ou individualmente o significado de suas ações (GIL,2008).

O estudo é composto de dados primários e secundários, sendo que os de origem primária foram obtidos na pesquisa realizada in loco com as pescadoras artesanais com aplicação da metodologia descrita acima. Ao passo que os dados secundários foram levantados através de pesquisa documental e bibliográfica analisando teses, dissertações, artigos e demais publicações que subsidiaram a compreensão do tema em estudo.

Os dados usados nesse artigo são parte da pesquisa de campo ocorrida entre outubro de 2016 e janeiro de 2017, para fins de elaboração da monografia de conclusão de curso em economia. O critério de inclusão consistiu em as mulheres serem moradoras do Bairro Pérola do Maicá, pescadoras artesanais sócias do núcleo de base da Colônia de Pescadores Z-20 e que estivessem em pleno exercício de sua atividade produtiva.

De acordo com a coordenação do núcleo de base existem 19 (dezenove) pescadoras artesanais ligadas a organização. Com o uso dos critérios de inclusão préestabelecidos chegou-se ao número total de 08 (oito) pescadoras artesanais, representando aproximadamente $43 \%$ das pescadoras artesanais sócias do núcleo de base e residentes no bairro. Para coleta de dados foram realizadas visitas nas residências das pescadoras e no lago, a fim de conhecer seus ambientes familiar e de trabalho. Buscouse analisar questões de ordem social, econômica e suas dificuldades no desenvolvimento da atividade pesqueira. Para tanto, foram realizadas entrevistas contendo questões abertas e fechadas a fim de coletar informações das características socioeconômicas das participantes da pesquisa.

Apesar do público participante da pesquisa seguir os requisitos usados para inclusão no processo de coleta de informações, para encontrá-las usou-se a técnica denominada "snowball" ou "bola de neve", onde faz-se a escolha de um informante chave, que recebem a denominação de sementes, os quais indicam pessoas com o perfil escolhido para pesquisa, e assim consecutivamente, como resultado o número de entrevistados 
acontece de forma gradativa onde os próprios participantes do estudo indicam os que possuem as características estabelecidas como critério de inclusão (YIN, 2005; VINUTO, 2014).

Feita a coleta os dados foram organizados em um banco no programa Excel for Windows, para serem tabulados em seguida feita as devidas análises. Os dados socioeconômicos (número de dependentes, idade, número de filhos, quantidade de dependentes e renda familiar) foram dispostos em tabela e estudados por meio de estatística descritiva, método que auxiliou na padronização e análise dos dados.

\section{CARACTERIZAÇÃO SOCIOECONÔMICAS DAS PESCADORAS ARTESANAIS}

O recorte espacial da pesquisa é o Bairro Pérola do Maicá, localizado dentro da área urbana da cidade de Santarém, às margens do Lago do Maicá, um espaço que possui peculiaridades urbanas e rurais, e de acordo com dados da Prefeitura Municipal de Santarém (PMS, 2013) possui 440 famílias.

A ocupação desse território é consequência do processo de expansão urbana da cidade, seu povoamento se deu por pessoas oriundas da região da várzea do município e de outras localidades de rios e planalto. Por estar localizado às margens do Lago do Maicá tem características da região de várzea, em que a metade do ano fica alagadiça e a outra em terra firme (VIEIRA, 2013).

Os pescadores artesanais possuem domínio dos ciclos das espécies existentes na fauna e na flora demonstrando intensa relação com o ambiente natural, de onde depende sua sobrevivência (SILVA,2012). Dessa forma, as mudanças ocorridas recentemente no ambiente onde a pesquisa foi desenvolvida são facilmente percebidas pelas pescadoras, uma vez que afetam diretamente seu cotidiano e o ambiente que elas vivem. Os principais problemas ambientais a partir das percepções das pescadoras dizem respeito aos resíduos jogados a céu aberto, que para elas causa o aumento de animais peçonhentos e doenças.

Outra questão preocupante detectada a partir da percepção das pesquisadas diz respeito à criação de búfalos (Bubalos sp.) na região do lago do Maicá. Esse problema 
foi identificado por $82 \%$ das pescadoras. Trata-se de uma questão que tem ligação com outros problemas relatados, como a diminuição de aningais (Montrichardia sp.), da oferta de peixes, poluição da água e desmatamento. Além disso provoca conflitos entre criadores de búfalos e os usuários do espaço, uma vez que os animais rasgam as malhadeiras dos pescadores e invadem os terrenos das pessoas que residem próximo ao Lago do Maicá.

A criação de búfalos na várzea amazônica tem sido alvo de diversos estudos, segundo Cerdeira (2009, p. 28) "[...] a criação de búfalo na várzea tem sido causa de conflitos entre criadores e pescadores, assim como agricultores que têm suas áreas invadidas". Essa realidade assemelha-se com problemas já identificados por pesquisas realizadas na região de Pixuna do Tapará (região da Várzea, Santarém) por O’Dwyer, (2005), onde a criação de búfalos é uma ameaça à reprodução pesqueira e a vegetação aquática, como os aningais. Esta autora afirma ainda que "[...] o búfalo é considerado um dos maiores depredadores dos celeiros de peixe, pois vão comendo a vegetação aquática e assim afugentam as espécies [...]".

Outro problema enfrentado pelas pescadoras é a existência de pesca predatória (arrastão, uso de bombas entre outros) dentro do referido lago. Essa prática também chamou atenção, pois entre 55\% das pescadoras artesanais esse problema é parte de suas preocupações cotidianas. Esta prática põe em risco a reprodução natural dos peixes, bem como, a subsistência das famílias que consomem peixe como base alimentar. Este fato aproxima-se do que vem ocorrendo nos ecossistemas aquáticos (rios e lagos) no estado de Rondônia, que de acordo com Oliveira (2006, p.1) "[...] a pesca predatória e clandestina, praticada nos rios e lagos de Rondônia, estaria exterminando várias espécies de peixes nativos dos vales do Guaporé, Mamoré e Madeira".

Na concepção de Cerdeira (2009), a intensificação da pesca predatória no Lago do Maicá é considerada como retrocesso dentro da política da cogestão comunitária pesqueira, pois a região foi a primeira dentro do município a construir o acordo de pesca como instrumento de ordenamento pesqueiro. Nesse contexto, a iniciativa comunitária tem a finalidade de garantir o controle do uso desses recursos considerados de uso comum, tendo como base os conhecimentos tradicionais arraigados nas comunidades 
da várzea amazônica (ISAAC,1993; McGRATH et al, 2008).

Observou-se ainda que as entrevistas consideram o Lago do Maicá como um ambiente de alta importância (73\%) ou importante (27\%). Sendo que o ambiente é usado de forma diferente pelas entrevistadas, ao passo que $73 \%$ das pescadoras artesanais usam o Lago para exercer sua atividade econômica, 36\% utilizam como espaço de lazer e $9 \%$ para desenvolver atividade ligada ao turismo.

As pescadoras artesanais do bairro Pérola do Maicá, participantes desta pesquisa, possuem idade entre 40 e 65 anos, com média de 31 anos. No que se refere a escolaridade, $85,5 \%$ possuem o ensino fundamental incompleto e $14,2 \%$ possui o ensino fundamental completo. Os dados demonstram a baixa escolaridade das pescadoras artesanais. As interlocutoras da pesquisa alegam não terem tido oportunidade de estudar quando mais jovens, devido à dificuldade de acesso às escolas. Cabe destacar que $100 \%$ das pesquisadas afirmaram possuir dependência econômica da atividade pesqueira. Realidade que assemelha-se às demais pescadoras das comunidades de Santarém, que segundo afirma Santana (2016), 64\% possuem o ensino fundamental incompleto e o analfabetismo envolve uma parcela dessas pescadoras (7\%).

A baixa escolaridade das pescadoras artesanais já foi identificada em estudos realizados em comunidades onde a pesca artesanal é atividade predominante (MARUYAMA et al., 2009; LIMA et al., 2012; RAMIRES et al., 2012). Tomando como base a idade média encontrada é possível perceber que no período em que essas pescadoras estavam entre a infância e a adolescência o acesso à escola era difícil, pois existiam poucas unidades de ensino nas comunidades, além disso conciliar o horário do estudo com a pesca era complicado, contribuindo assim com a evasão escolar (SANTOS et al., 2005; BORCEM et al., 2011).

Outro dado a ser destacado, diz respeito ao número de filhos que as pescadoras possuem. Em média elas possuem mais de quatro filhos (4,5 filhos). Esse resultado está acima da média nacional, que corresponde a aproximadamente 3,1 filho, conforme dados do Instituto de Pesquisa Econômica Aplicada (IPEA, 2013). As informações levantadas demonstram que a baixa escolaridade pode influenciar na quantidade de filhos que a mulher possui. De acordo com Varela (2011), as mulheres que possuem o nível 
fundamental incompleto têm em média 4,4 filhos, no caso em tela foi percebido que as pescadoras assumem a responsabilidade de ser mãe muito jovens, com demonstrado nos dados acima.

No que se refere à questão de moradia, todas as pesquisadas têm residência própria. Sendo que 57,2\% residem em casa com estrutura em alvenaria; e 14,2\% possuem a residência construída em madeira (Gráfico 1).

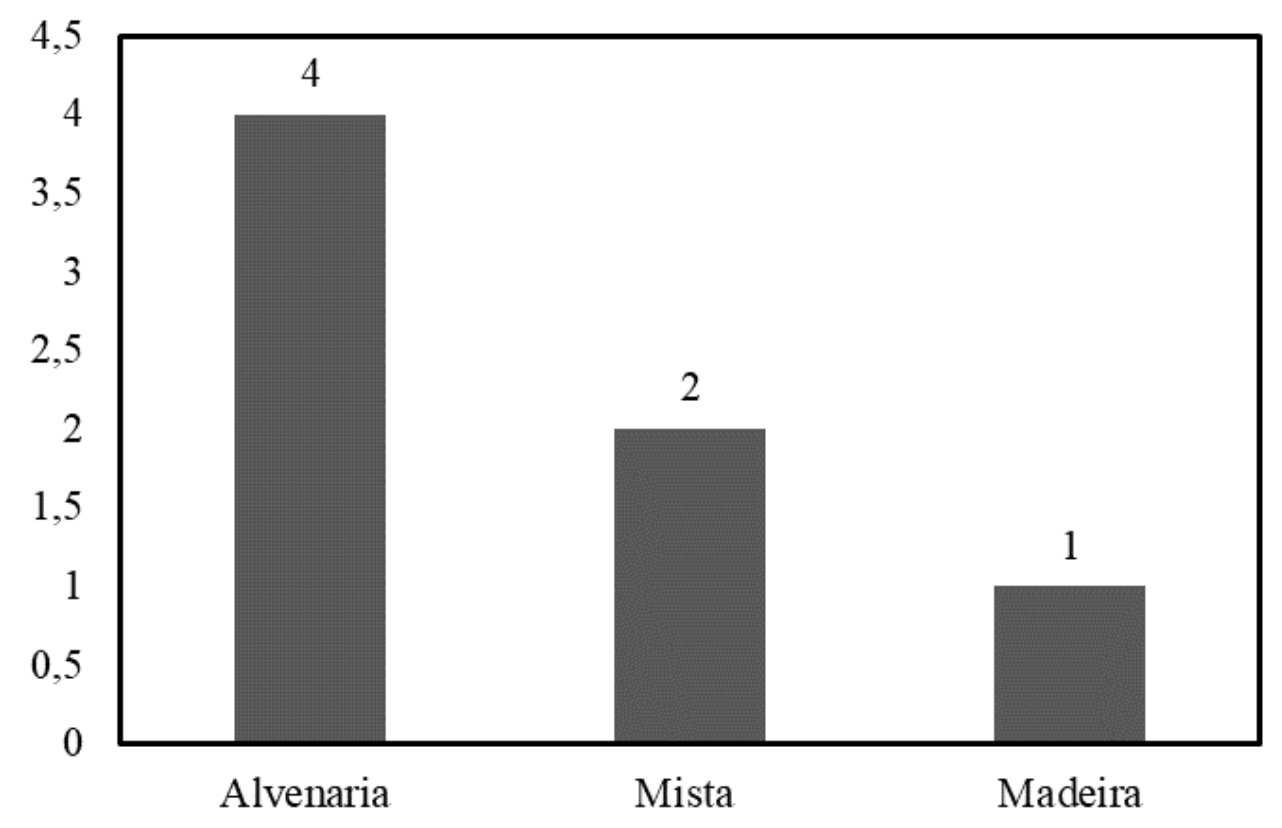

Figura 1. Gráfico sobre moradia das pescadoras artesanais do Bairro Pérola do Maicá, Santarém, Pará. Fonte: Dados da pesquisa.

Sobre o acesso ao abastecimento de água, as informações levantadas mostram que $85,8 \%$ utilizam água de poço ou nascentes dentro da sua propriedade e apenas $14,2 \%$ tem acesso à rede de distribuição de água existente no bairro (Micro-Sistema da Prefeitura). As dificuldades para haverem garantidos os direitos básicos como o de saneamento básico são situações corriqueiras no cenário político e social do país, em Santarém não é diferente, especialmente nos bairros periféricos da cidade.

É cristalina a fragilidade na execução de políticas públicas importantes para sobrevivência da população, dando assim abertura para que a população construa seus próprios meios de obtenção de acesso à água. Além disso, não está em consonância com um dos objetivos do milênio, que indica o acesso à água é fundamental para que todos tenham vida digna. Conforme afirma Machado (2016, p.5), "o objetivo de Número 
6 propõe a garantia da disponibilidade e o gerenciamento sustentável da água e do saneamento básico para todos".

Em relação ao acesso ao serviço fundamental de saneamento básico, o estudo revela que na residência da maioria das pescadoras utilizam-se fossa séptica, o que representa $71,4 \%$ das pesquisadas e $28,6 \%$ lançam seu esgoto na rede pluvial. Confirmando a fragilidade que essas pescadoras enfrentam para ter acesso à qualidade de vida adequada, uma vez que os dejetos despejados de uma forma ou outra prejudicam a saúde das pesquisadas, de sua família e do entorno.

A deficiência do serviço de esgotamento sanitário e de abastecimento de água é o mesmo vivenciado pelas comunidades que vivem na região da várzea amazônica no qual as "comunidades não dispõem de estrutura básica de ensino médio, posto de saúde e possuem abastecimento precário de água, bem como de saneamento" (MARTINS, 2009, p. 63). Quanto ao acesso à energia elétrica, $100 \%$ possuem esse serviço, assim como a coleta de lixo, feita pela prefeitura.

Quanto ao estado civil do universo participante do estudo, 58\% vivem em união estável e $42 \%$ declararam ser solteiras, o que demonstra que existe um número expressivo de mulheres que assumem a responsabilidade integral da família. As participantes da pesquisa sobrevivem unicamente da pesca artesanal há mais de 10 anos. Ressaltase que todas são oriundas de comunidades da várzea da região do Baixo Amazonas, onde a pesca artesanal é a principal atividade econômica exercida. No que se refere ao rendimento obtido com a realização da atividade da pesca artesanal, todas declaram que seu rendimento diário médio, obtido pela comercialização do pescado, gira em torno de $\mathrm{R} \$ 62,14$ por dia.

Observa-se que as pescadoras declararam que dedicam- se em média 16 dias à pesca no lago, sua ocupação principal e o restante dos dias são dedicados para cuidar da família, da casa e da recuperação dos arreios usados durante a pescaria, demonstrado que elas não contabilizam o esforço dedicado no cuidado a casa e a família. Essa compreensão diverge dos pressupostos da nova visão da economia feminista que propõe a valorização do esforço feminino de forma mais abrangente, incluindo o esforço produtivo remunerado e não renumerado (NOBRE; FARIA, 2002). 
O novo paradigma da economia feminista fortalece o entendimento de Fassarela (2007, p.46) onde afirma que "[...] o trabalho de homens e mulheres deve ser valorizado como produtivo". Essa nova concepção soma-se ao arcabouço de conquistas como direito ao voto, a inserção nos espaços públicos e políticos entre outros conquistados ao logo do tempo.

Algumas pescadoras declararam que desenvolvem como atividade complementar a agricultura familiar, produzindo hortaliças e criando pequenos animais. No entanto, a maioria sobrevivem exclusivamente da pesca artesanal sendo "uma das principais fontes de alimentos, bem como de geração de renda" (VIEIRA, 2013, p.4-5).

No bairro, estão cadastrados no núcleo de base 44 pescadores artesanais, desse total, 19 são mulheres que sobrevivem exclusivamente da pesca. O núcleo de base existe desde 1996, foi fundado por aproximadamente 20 (vinte) pescadores artesanais oriundos da região da várzea do município, precisamente das comunidades "Arapemã, Ilha do Bom Vento, Pindurí, Igarapé do Costa, Tapará, Aracampina, Ituqui e Lago Grande" (SOUSA, 2017, p.41).

O núcleo de base reúne-se uma vez por mês para dialogar sobre sua organização e construir propostas de conservação dos recursos pesqueiros e do ecossistema do Lago do Maicá. Desde sua fundação o núcleo de base do bairro teve a frente de sua coordenação apenas uma mulher, Maria Anália Sousa Costa, que coordenou os pescadores em dois mandatos no período de 2005 a 2008 e novamente de 2012 a 2015. Atualmente, o núcleo de base é coordenado pelo pescador Benedito Chagas Coelho, empossado em 2016.

As atividades de pesca e comercialização do pescado são realizadas primordialmente entre os meses de abril outubro, período que é liberado para a pescaria artesanal, de março a novembro não realizam a atividade em respeito ao período de defeso das espécies. No entanto, existem espécies que são pescadas em períodos distintos como é o caso do tambaqui e do acari que possuem períodos específicos de defeso. 


\section{CONSIDERAÇÕES FINAIS}

A atividade da pesca artesanal é realizada por meio da pactuação de parcerias, promovendo ampla participação das mulheres. Dessa forma, é essencial refletir sobre as formas de divisão sexual do trabalho e a distribuição do poder, bem como, as várias responsabilidades que as mulheres assumem na pesca artesanal e na sociedade em geral.

Apesar das pescadoras artesanais terem conseguido alguns avanços dentro da atividade pesqueira, a invisibilidade de sua produção ainda é um entrave que não foi vencido, principalmente dentro de suas entidades representativas da classe, a exemplo das diretorias das Colônias de Pescadores que, em sua maioria, são ocupadas por homens, situação já debatida por Maneschy et al (1995), cuja invisibilidade enfrentada por essas mulheres vai desde o âmbito da presença feminina na pesca, a respectiva produção pesqueira e culmina na dificuldade de articulação política nos movimentos sociais do setor.

No cenário do núcleo de base do bairro Pérola do Maicá, da Colônia de Pescadores Z-20, as pescadoras se deparam com inúmeras adversidades para desenvolver sua principal atividade econômica. O processo de organização delas na Amazônia precisa ser estudado profundamente, enfocando na diferenciação relacionada às questões de gênero existente no contexto do setor pesqueiro. Deve-se trabalhar para aumentar a capacitação e qualificação das pescadoras, haja vista que a pesquisa revelou existir uma baixa escolaridade, que pode representar em dificuldade no acesso às políticas públicas para obter uma melhor qualidade de vida.

Um fato que merece atenção é a inexistência de informações sobre o esforço produtivo e atuação nas organizações sociais e políticas dentro da cadeia produtiva da pesca. Essa lacuna ajuda a fortalecer a desvalorização da produção feminina, como sujeitos importantes dentro da sociedade. Dessa forma, é necessário valorizar as características das atividades exercidas pelas mulheres no setor pesqueiro, pois assim, será reconhecido sua dedicação na organização familiar, organizacional e produtiva.

Sugere-se que as Instituições de pesquisa que abordam o tema realizem atividades em conjunto com as pescadoras artesanais para ajudá-las na discussão de políticas 
públicas que garantam seu reconhecimento enquanto classe produtiva e ajudem no desenvolvimento sustentável da pesca artesanal.

\section{Referências}

ALENCAR, E. F.; PALHETA, S. P.; SOUSA, I. S. de. Trabalho na Pesca, ação política e identidade: as mulheres da Colônia de Pescadores Z-32 de Maraã, Amazonas. In: SCHERER, Elenise F. "AQUI ESTAMOS NÓS": entre as águas dos mares, nas águas dos rios, nas terras de trabalho na pesca artesanal. Rio de Janeiro, Garamond, 2015.

ALENCAR, E. F.; Questões de gênero em projetos de manejo de recursos pesqueiros na reserva de desenvolvimento sustentável Mamirauá. Seminário internacional fazendo gênero 10 (anais Eletrônico). Florianópolis, 2013.

ALMEIDA, I.C. O papel da pesca na eficiência reprodutiva dos ribeirinhos do Baixo Tocantins: O caso do município de Mocajuba - PA. Dissertação (Mestrado em Desenvolvimento Sustentável do Trópico Úmido) - Universidade Federal do Pará, Núcleo de Altos Estudos Amazônicos, Belém, 2013. p.118.

BOURDIEU, Pierre. A Dominação Masculina. Rio de Janeiro: Ed. Bertrand Brasil, 2003. BORCEM, E. R.; FURTADO JÚNIOR, I.; ALMEIDA, I. C.; PALHETA, M. K. S.; PINTO, I. A. A atividade pesqueira no município de Marapanim-Pará, Brasil. Revista de Ciências Agrárias, 54 (3), 189-201, 2011.

CERDEIRA, R. G. P. Acordo de pesca como Instrumento de Gestão Participativa na Amazônia. Dissertação apresentada ao Programa de Pós-Graduação em Direito Ambiental da Universidade do Estado do Amazonas como um dos requisitos para obtenção do grau de Mestre em Direito Ambiental. 2009. p.133.

FASSARELA, Simone S. A vez e a voz das mulheres que atuam em atividade de pesca davila São Miguel (RS) Trajetórias e Perspectivas. 116f. Dissertação (Mestrado em Educação Ambiental), Fundação Universidade Federal de Rio Grande, Rio Grande, 2007

FIGUEIREDO, M. M. A.; PROST, C. O Trabalho da mulher na cadeia produtiva da pesca artesanal. Revista Feminismos, vol.2, n.1, p.82-93, 2014.

GIL, Antônio Carlos. Como elaborar projetos de pesquisa. 4. ed. São Paulo: Atlas, 2008. HELLENBRANDT L; RIAL, C; LEITÃO, M. R. F. A. Pesca e gênero: reconhecimento legal e organização das mulheres na "colônia z3" (Pelotas/RS - Brasil). Revista Vivência (Antropologia). Volume 1, Número 47, p. 123 - 136, 2016. Acesso em 25 de julho de 2018. Link para acesso: https://periodicos.ufrn.br/vivencia/article/view/11651.

HOFFMANN, R.; LEONE, E. T. Participação da mulher no mercado de trabalho e desigualdade da renda domiciliar per capita: 1981-2002. Revista Nova Economia, v.14, 2004.

IPEA, 2013. Programa Bolsa Família uma década de inclusão e cidadania. Disponível em: http://www.ipea.gov.br/sites/000/2/publicacoes/tds. Acesso em: 10 de julho de 2017.

ISAAC, V. J.; BARTHEM, R. B. Os recursos pesqueiros da Amazônia Brasileira. Boletim do Museu Paraense Emílio Goeldi, p.295-339. 1995. 
KERGOAT, D. Divisão sexual do trabalho e relações sociais de sexo. In TEIXEIRA, M., EMÍLIO, M., NOBRE, M. e GODINHO T. (org.). Desafios para as políticas públicas: trabalho e cidadania para as mulheres. São Paulo, 2003. p. 55-64.

LEITÃO, M. R. F. Andrade. Gênero, pesca e cidadania. Revista Amazônica. Volume 5, Número 1, 2013, p. 98 - 115. Acesso em 15 de agosto de 2018. Disponível em:https://periodicos.ufpa.br/index.php/amazonica/article/view/1307/1718

LEONE, E. T; TEIXEIRA, M. O. As mulheres no mercado de trabalho e na organização Sindical. XVII Encontro Nacional de Estudos Populacionais, Caxambu- MG, 2010.Disponível em:http://www.abep.org.br/publicacoes/index.php/anais/article/view/2289/2243. Acessado em: 10 de agosto de 2017.

LIMA, C. M. de; LEITÃO, M. do R. de F. A. Transversalidade de gênero e políticas para produtiva da pesca artesanal nas comunidades de Brasília Teimosa e Itapissuma (PE/Brasil). Revista Vivência: Revista de Antropologia. Natal: 2014. p. 123-134. Acesso em: 30 de julho de 2017. Disponível em:https://periodicos.ufrn.br/vivencia/article/view/6809/5243

LIMA, M. A. L.; DORIA, C. R. C.; FREITAS, C. E. C. Pescarias artesanais em comunidades ribeirinhas na Amazônia Brasileira: perfil socioeconômico, conflitos e cenário da atividade. Ambiente \& Sociedade, São Paulo, 15 (2), 73-90, 2012.

MACHADO, A. V. M. et. al. Acesso ao abastecimento de água em Comunidades Rurais: o desafio de garantir os direitos humanos à água. XII Congresso Nacional de Excelência em Gestão \& III INOVARSE - Responsabilidade Social Aplicada. 2016. p.14. Disponível em: http://www.inovarse.org/sites/default/files/T16_203.pdf. Acesso em: 30 de julho de 2017.

MANESCHY, M. C. A mulher está se afastando da pesca? Continuidade e mudança no papel da mulher na manutenção doméstica entre famílias de pescadores no litoral do Pará. Boletim do Museu Paraense Emilio Goeldi. Antropologia, v. 11, n.2, 1995, p. 145-166.

M. C; ALENCAR, E; NASCIMENTO, I. H. Pescadoras em busca de cidadania. In: ÁLVARES, M.L.M; D’Incao, M. A. A mulher existe? Uma contribuição ao estudo da mulher e gênero na Amazônia. Belém: GEPEM, 1995, p. 81 - 96.

MARTINS, E. de V. Dinâmica da economia e das relações do trabalho da pesca artesanal no município de Santarém. Dissertação (Mestrado em Desenvolvimento Sustentável do Trópico Úmido) - Universidade Federal do Pará, Núcleo de Altos Estudos Amazônicos, Belém, 2009. 105 p. 106

MARTINS, M. L. S.; ALVIM, R. G. Perspectivas do trabalho feminino na pesca artesanal: particularidades da comunidade Ilha do Beto, Sergipe, Brasil. Boletim do Museu Paraense Emílio Goeldi. Cienc. Hum, v. 11, n. 2, p. 379-390, 2016.

MARUYAMA, L. S.; CASTRO, P. M. G.; PAIVA, P. Pesca artesanal no Médio e Baixo Tietê, São Paulo, Brasil: aspectos estruturais e socioeconômicos. Boletim do Instituto da Pesca, São Paulo, 35 (1), 61-81, 2009.

McGRATH, D.G.; CARDOSO, A.; ALMEIDA, O.T.; PEZZUTI, J. Constructing a policy and institutional framework for an ecosystem-based approach to managing the Lower Amazon floodplain. Environment, Development and Sustainability, v.10, n.1, p.677-695, 2008. 
NOBRE, M.; FARIA, N.. (orgs). Economia feminista. São Paulo: SOF, 2002. Cadernos Sempre Viva, p.104

O' DWYER, E.C. A construção da várzea como problema social na região do Baixo Amazonas. In: LIMA, D. (Org.) Diversidade socioambiental nas várzeas dos rios Solimões e Amazonas. Manaus: Ibama/Provarzea, 2005. p.207-264.

OLIVEIRA, D.; SAMPAIO, S. Mercado de trabalho industrial e a questão do "gênero": uma análise do trabalho feminino em indústrias de Rio Claro, São Paulo. Revista de Geografia, Rio de Janeiro, v.2, 2002.

OLIVEIRA, V. B. V. de; SILVA, R. M. P.; AZEREDO, C. D. A. dos S.. Gestão da Pesca Artesanal no Contexto Socioambiental do Lago Cujubim Grande, Porto Velho-Ro. (2006). Resumo enviado para o GT - 27 A pesca em áreas rurais, sustentabilidade sócio, política e ambiental, Quito, Ecuador.

OLIVEIRA, M. M. de. Como fazer pesquisa qualitativa. $2^{a}$ edição. Petrópolis, Rj: Vozes, 2008. p. 184 .

PINTO, W. O trabalho invisível das mulheres pescadoras. Jornal da Universidade Federal do Pará. v.30, n.130, 2016. Disponível em: . Acessado em: 10 de agosto de 2017.

PREFEITURA MUNICIPAL DE SANTARÉM - PMS. Secretaria Municipal de Meio Ambiente. Centro Municipal de Informações Ambientais - CIAM. In: INFORMAÇÕES MUNICIPAIS DE SANTARÉM SEMMA_CIAM. Publicado em 2013. Disponível em:http://www.jornalbeiradorio.ufpa.br/novo/index.php/2004/59-edicao-19/659-otrabalho-invisivel-das-mulheres-pescadoras. Acesso em: 24 de julho de 2017.

RAMIRES, M.; CLAUZET, M.; ROTUNDO, M. M.; BEGOSSI, A. A pesca e os pescadores artesanais de Ilhabela (SP), Brasil. Boletim do Instituto de Pesca, São Paulo, 38 (3), 231-246, 2012.

SANTANA, C. G. dos S. O Saber das Amazônidas: o protagonismo das mulheres na atividade de pesca em Santarém, Pará. Monografia (Programa de Ciências Econômicas e Desenvolvimento Regional) - Universidade Federal do Oeste do Pará, Instituto de Ciências da Sociedade, Santarém. 2016. p. 54

SANTOS, Á. O. et.al. A (In)Visibilidade das Mulheres Agricultoras Familiares do Município de Santarém-Pará nas Políticas Públicas. $1^{\circ}$ Simpósio SOBER NORTE: "A crise econômica e o futuro a agropecuária no Norte: desafios e potencialidades. Belém, Pará. 2017. p. 4.

SANTOS, M. A. S.; FILHO, M. C. S. G.; NEVES, P. R. S.; AGUIAR, C. G. G. Análise socioeconômica da pesca artesanal no Nordeste Paraense. In: XLIII Congresso da Sober: Instituições, Eficiência, Gestão e Contratos no Sistema Agroindustrial. Anais. Ribeirão Preto, 2005.

SORJ, B. Os cuidados com a família e as desigualdades de gênero e de classe. In: COSTA, A; ÁVILA, M. B.; SOARES, V.; FERREIRA, V (org). Divisão sexual do trabalho, estado e crise do capitalismo. Recife: SOS Corpo, 2010, p. 57 - 65.

SOUSA, W.L. Caracterização Econômica e Social dos Pescadores Artesanais no Bairro Pérola Maicá, no Município e Santarém-Pará. Monografia (Programa de Ciências Econô- 
micas e Desenvolvimento Regional) apresentado ao Instituto de Ciências da Sociedade da Universidade Federal do Oeste do Pará (UFOPA). 2017. p. 76

SILVA, R. E.. Guiados por Mares e Peixes: memória social, inovação tecnológica e o processo de fragmentação na pequena pesca comercial simples em duas comunidades costeiras no Rio Grande do Norte. 2012. Tese apresentada ao Programa de Pós Graduação em Sociologia da Universidade Federal da Paraíba. João Pessoa. p.278

VAZ, E.de M. Caracterização da atividade pesqueira praticada no Lago Maicá, Município de Santarém, Pará. Santarém - Pará. Trabalho de Conclusão de Curso apresentado no Curso de Bacharelado em Engenharia de Pesca, da Universidade Federal do Oeste do Pará, Campus Santarém. 2016. p. 49.

VIEIRA, J. C. Quilombolas na Cidade: Dilemas do Planejamento Urbano Frente ao Território do Quilombo do Maicá em Santarém-Pará. In: XXII Encontro Nacional do Conselho Nacional de Pesquisa e Pós-Graduação em Direito, 2013, Curitiba-PR. Disponível em: http://www.publicadireito.com.br/artigos/?cod=6f8805c87ad80ed9. Acessado em: 22 de julho de 2017.

WOORTMANN, Ellen F. Da Complementaridade à Dependência: espaço, tempo e gênero em comunidades pesqueiras do Nordeste. Revista Brasileira de Ciências Sociais. Rio de Janeiro, v. Ano 7, n.18, p. 41-61, 1992 . Acesso em 15 de agosto de 2018. Link para acesso: http://anpocs.org/index.php/publicacoes-sp2056165036/rbcs/219-rbcs-18\#4 